\title{
Impacts of vessel speed on bunker cost in short sea shipping: A cross-examination
}

\author{
Esa Hämäläinen ${ }^{1}$, Tommi Inkinen ${ }^{1, ~ *}$ \\ ${ }^{1}$ Brahea Centre, University of Turku, 20014 University of Turku, Finland
}

\begin{abstract}
Air emissions of shipping have decreased in SECA regions after 2015. Environmental impacts of regulation policies are identifiable and measurable, as a study from the port of Gothenburg recently exposed. In addition to emissions, it is important to understand how regulations and decisions, focusing on environmental sustainability, impact on the maritime business indicators such as transport costs and marginal revenues. When SECA decision was made, the oil and bunker prices were historically high. Prices were also highly volatile. Numerous studies estimated difficulties for shipping companies, and maritime transport dependent export companies. The oil price dropped dramatically in 2016 remaining at the same level till the early 2018 . This empirical case study examines and simulates bunker price data in relation to different vessel speeds. The paper looks at how different speed and oil price combinations impact transport costs and export business. The results of this simulation can be summarized with the notion that the negative economic impacts of the oil price variation can be mitigated to some extent by using lower vessel speeds, thus slow steaming, on short sea shipping (SSS). However, variable relations are not straightforward and they require additional studies.
\end{abstract}

\section{Introduction}

The purpose of this study is to examine that how does slow steaming, together with four different bunker price options, impact on the essential key-figures of logistics. Original research data was obtained from a Big Data solution of a single paper mill (also [1]). This Big Data covers all the cost, product, logistics, invoice information, and allocations to market areas (destinations). The authors analyze how slow steaming combined with various (and increasing) bunker price variables would impact on the gross margin of the company. In the earlier studies, the authors [2,3,4] expected that bunker prices would even more than double, which did not happen.

Globally ship transportation (per a transported unit) has been considered to be the most environmentally friendly transport mode. Yang et al. [5] noted from a Taiwanese perspective that internal green practices and external green collaboration have positive impacts on green performance, which in turn helps to enhance company competitiveness. However, these arguments do not take into account the rising fuel costs that form a

\footnotetext{
* Corresponding author: tommi.inkinen@utu.fi
} 
significant part of ship's operating costs, if new innovations and working solutions are not presented. Lindstad et al. [6] claim in their paper that emissions can be reduced up to $30 \%$ with a negative abatement $\mathrm{CO} 2$ cost per ton, if the existing fleet is replaced with larger vessels. Replacing old vessels may take as long as 25 years, so the anticipated reduction in emissions will be achieved gradually while the current fleet is being renewed. This argument is based on the assumption that the existing heavy fuel oils (HFO) are used as bunker fuels. Based on the above considerations, the main focus of this paper is to analyze the following two points:

- Conduct simulation calculations by using realistic bunker prices.

- Cross-examine, how bunker prices and lower speed (thus lower bunker consumption) have an impact on the economic key-performance indicators (KPIs) used by companies (such as gross margins and transport costs in $€ /$ Ton)?

\section{About slow steaming and bunker consumption}

Oil price skyrocketed to the all time high in 2008 (Fig. 1) and then dropped as dramatically. Currently, oil price has started to rise slowly, but reliable prediction of the level it will rise, and probably stay on, is difficult to estimate. In the cases, when oil price soars unexpectedly, shipping companies quickly realize and understand the need for new steaming solutions and vessel upgrades needed to be developed in order to lessen the impacts of high bunker costs on sea freights. Container shipping company Maersk have ordered the new large ships as large as 23000 TEU and these have design speeds lower than the current ones (19 knots versus 25.5 for the Emma Maersk). The company calculated that they would operate at a fuel consumption of 50\% less than the average industry, and also $20 \%$ more efficiently than the existing best. Slow steaming is practiced not only in the container market, although it may seem to make more sense due to higher container ship speeds as it is reported in every market. In December 2010, Maersk Tankers was reported to have their Very Large Crude Carriers (VLCCs) sailing at half the speed of a container ship. The design speed of 16 knots was reduced to speeds less than 10 knots on almost one third of its ballast legs, and between 11 and 13 knots on over one third of its operating days. For example, a typical round trip voyage from the Persian Gulf to Asia normally takes 42 days (at 15 knots laden and 16 knots in ballast). Maersk Tankers decreased ship speed to 8.5 knots on the ballast leg, thus increasing the round trip time to 55 days and saving nearly $\$ 400,000$ off the voyage's bunker bill [7].

Globally there are different regions for different bunkers, so when a ship is entering a bunker-restricted region, they have to change their bunker fuel to cleaner and more expensive Marine Diesel Oil (MDO), or use other solutions, such as a combination of the HFO and scrubbers, which remove sulphur from bunker fuel. The effect of oil prices on shipping can be directly translated into increased bunker costs. Fuel costs represent as much as $25-60 \%$ of total ship operating costs, depending on ship and service types [8]. Among the Nordic export industries, the SECA decision is expected to increase discussions regarding new, alternative and relevant multimodal transport routes. These should be costefficient and capable of handling and regularly transporting large cargo volumes (see e.g. $[9,10,11])$. Accurate business forecasting in transportation is a real challenge, especially for the Finnish paper industry [3]. 


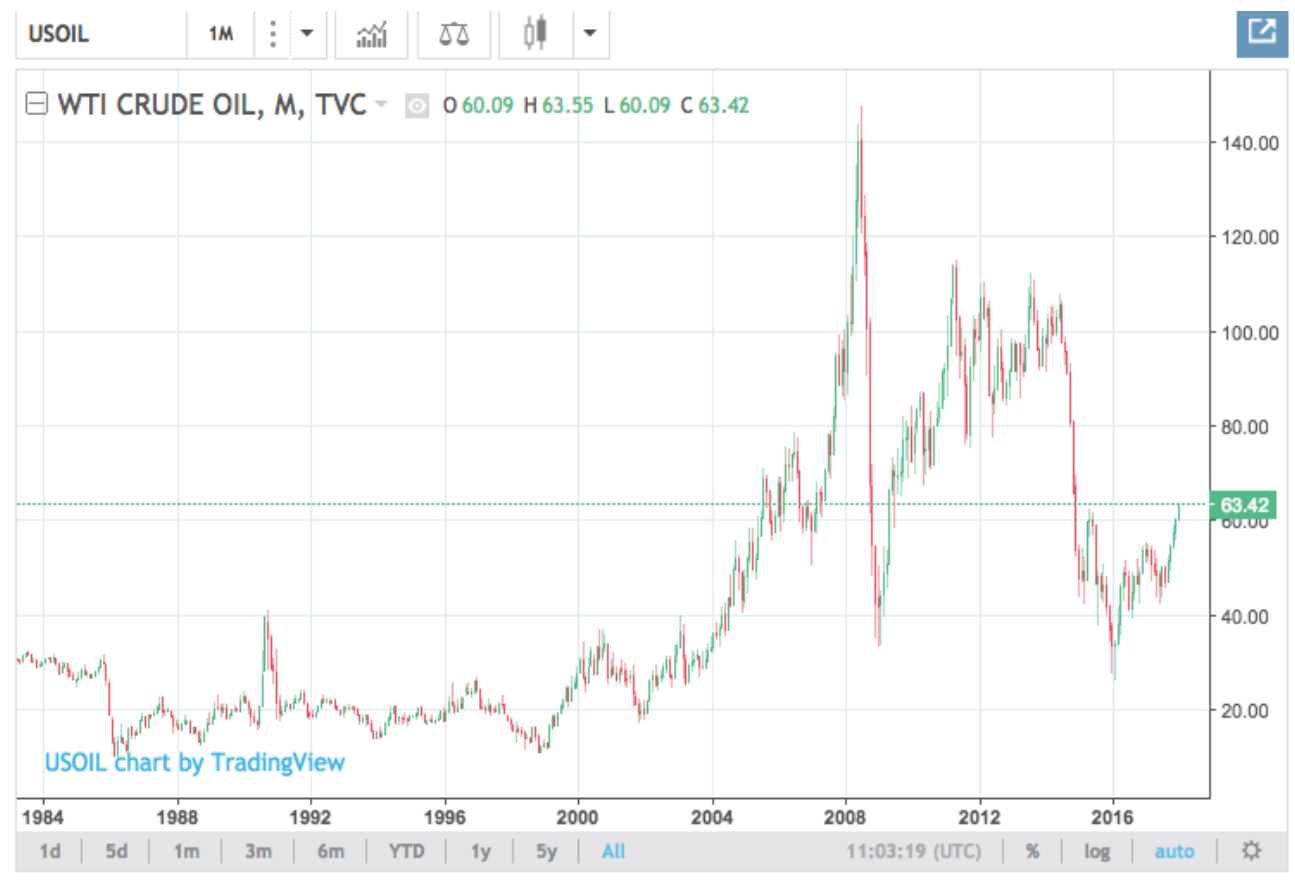

Fig. 1. Development of crude oil price since 1984.

\section{Case data and the forecasting method}

This study focuses on examining how slow steaming would impact bulk industry in the Baltic and North Sea region with different anticipated bunker prices. The relationship between slow steaming and the forecasted bunker costs was revealed by utilizing empirical data obtained from a paper mill located in Southern Finland and relatively close to an exporting port. The Nordic paper mills are normally integrated sites consisting of pulp processing, paper manufacturing, and a complicated mixture of converting, warehousing, transportation and cost management functions. This value chain covers the process functions from timber yard to end customers [2, 3, 4]. As background the case mill transports its final products mainly to the European markets $(70 \%)$ and about $10 \%$ goes to the domestic customers.

The longitudinal data was obtained from the case mill's cost management SQL database (also [1]). This quantitative database stores the mill's production as well as economic, transportation and logistical information. Applied variables have been transformed into a single large dataset, based on packed net tons and Euro, and the parameters are calculated mainly in $€ /$ Ton, or in percentages, which gives the possibility to make relevant comparisons. The results of the calculations are shown in ratio to maintain business confidentiality, and the key-objective is to determine relevant value-added factors.

The method explaining how the research data was generated for forecasting calculations in order to simulate situation (with various bunker prices and various lower bunker consumption variables) is presented below:

1. From the acquired dataset, sea transportation costs were obtained. Transportation costs from the Nordic countries to Europe correlate significantly with oil prices, 
and it was estimated that in 2017 the transportation costs will be slightly higher than at the level of 2014. Fig. 1 supports this assumption.

2. The data covers individual sea transport costs to four large European export countries.

3. The paper prices of the mill were compared with the prices received from the FOEX, which presents the latest market prices in Europe. The prices have stabilized at the level of 2009.

4. Variable and fixed costs were calculated and estimated from the values of 20082009, and it was forecasted how they will be in 2015 and onward. Additionally, there were discussions with the mill staff about the cost level. The mills have been able to stabilize manufacturing costs to match the level of 2009.

5. Notteboom et al. [8] have concluded that ship fuel costs, as a percentage of total daily operating costs, vary heavily from $25 \%$ up to $65 \%$ depending on ship type. In these forecasting calculations, $45 \%$ was used as a fuel cost-coefficient.

6. As to estimating total transport costs in 2017 with slow steaming, there was an added $10 \%$ extra costs driver; total sea freight costs in Euro per ton minus anticipated fuel costs of sea freights per ton $=$ other operating costs per tons, and this figure was multiplied by $1.1(10 \%)$ to take into an account the increased capital and warehousing costs in Euro per ton of cargo. As an example (100€-45€ $=55 € \rightarrow 55 € * 1.1=60.50 € \rightarrow 45 €+60.50=105.50)$. This $10 \%$ coefficient covers also other additional expenses, which will be charged from shippers including increases in salaries and vessels maintenance costs. These costs have a tendency to increase freight prices [12].

\section{Findings and results}

In Fig. 2, it is anticipated how the change of bunker costs $(-25,0,25$ or $50 \%$ of the existing cost) together with different bunker consumption estimations $(0,-25$ and $-50 \%$, these are based on slow vessel moving) have an effect on transport costs (\%). Fig. 2 shows that if speed is optimal then the transport cost percent increases clearly linearly either if bunker price lowers from existing price by $-25 \%$, stays as 0 or increases by $25 \%$ or $50 \%$. The authors want to expose the transport costs to four separate markets with previous described logistics variables. It is assumed that fuel costs are $45 \%$ of a ship's operating costs. The updated research data shows that if bunker price increases by $25 \%$ then transport costs percent per ton freight increases by $8 \%$ (see Fig. 2, Country 3). We have assumed that shipping companies add any rising fuel costs as such to freight prices, and therefore freight prices (transport cost from shipper's perspective) will certainly increase. Fig. 2 shows clearly that even bunker costs increases by $25 \%$ or even $50 \%$ transport costs go down by several percentages when ships start to utilizing lower speed as savings method when sailing. 


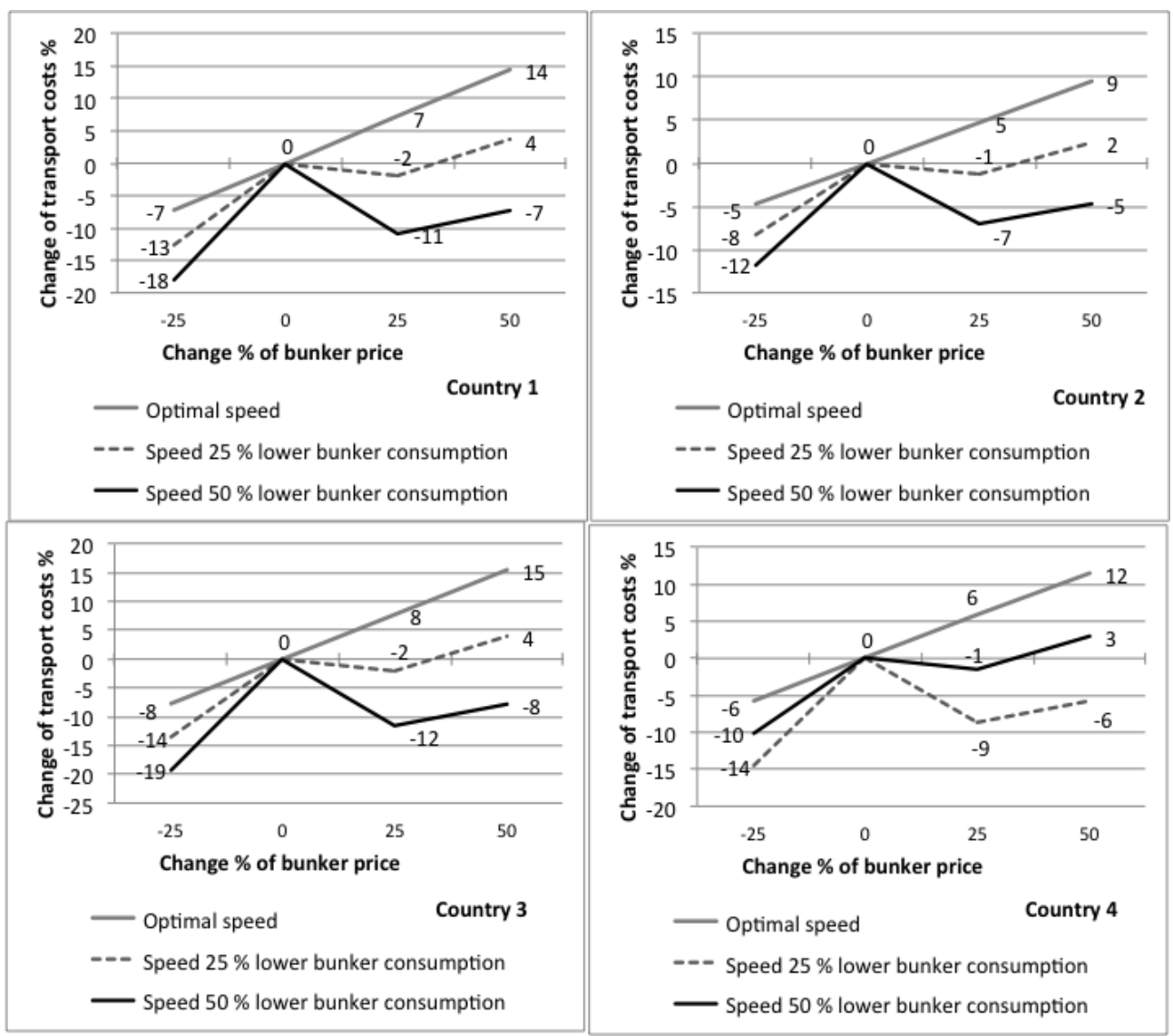

Fig. 2 Change of transport costs in $\%$ with four different fuel costs parameters: $-25 \%, 0,25 \%$ and $50 \%$ lower bunker consumption.

\section{Discussion and conclusions}

Before the SECA decision 2014 there were strong opinions stating that maritime transport will face on significant cost challenges because of the oil price development. At the same time also slow steaming was launched as a method to mitigate high oil price impacts. This study presents some anticipatory analysis with cross calculations between oil price development and slow steaming. The study exposes clearly that if bunker price increases, even up to $50 \%$ of the current level, there are means to mitigate this cost impact by sailing vessels slower, or even at the same speed but with larger cargo ships reducing the cost per unit. After 2015, when oil price decreased dramatically to their current levels, pressure to low steaming has decreased. However, oil prices in future are highly dependent on global politics and therefore sudden and drastic turns in oil/bunker prices are possible.

This study applied fresh data and presented different scenarios particularly for the Nordic export industry that is heavily reliant on SSS. The study expressed that cost savings by using slow steaming could be up to $25 \%$ depending on bunker cost development (see 
[13]). The results also indicate how transport variables and their joint development impacts on gross margin, which is an important KPI in the paper industry. Transport cost has a direct impact on margins and the study argues that slow steaming in soaring price development is a viable method keeping transport costs under control.

This analysis addressed that there are variations between export markets due to different types of transport chains. The authors note that whole SSS industry, as well as logistics and supply chains, should work together if sudden changes occur in logistics business environment. Extrapolation results of this research should limit for transportation of large volumes bulky products. Usually every cargo group and sea length needs specific research on how slow steaming has an effect on freight prices. Impacts of slow steaming in SSS routes are clear and they vary according to different markets.

\section{References}

1. Hämäläinen, E. and Inkinen, T. 'How to generate economic and sustainability reports from Big Data? Qualifications of process industry', Processes, Vol. 5 No. 4: 64 (2017)

2. Hämäläinen, E. 'Cost efficiency of supply chain in a Nordic paper mill - A case study', International Journal of Management, Vol. 28 No. 3, pp. 945-958 (2011)

3. Hämäläinen, E. Economic geographical analysis of the Finnish Paper Industry. Annales Universitatis Turkuensis, SER A11 - TOM. 263. Turku. (2011)

4. Hämäläinen, E. 'Economic geographic characteristics in the Finnish paper industry - a case study', Fennia, Vol. 189 No. 2, pp. 63-75. (2011)

5. Yang, C-S., Lu, C-S, Haider, J. J. and Marlow, P. B. 'The effect of green supply chain management on green performance and firm competitiveness in the context of container shipping in Taiwan', Transportation Research Part E, Vol. 55, pp. 55-73 (2013)

6. Lindstad, H., Asbjørnslett, B. E. and Strømman, A. H. 'The importance of economies of scale for reductions in green house gas emissions from shipping', Energy Policy, No. 46, pp. 386-398 (2012)

7. TradeWinds (2010) 'Slow spur for Maersk VLCCs', TradeWinds Magazine, 13 December.

8. Notteboom, T., Delhaye, E. and Vanherle, K. Analysis of the Consequences of Low Sulphur Fuel Requirements. Report commissioned by European Community Shipowners' Associations (2010)

9. AECOM Rail Baltica Final Report: Volume I, AECOM Limited, Chelmsford (2011)

10. AECOM Rail Baltica Final Report: Volume II, AECOM Limited, Chelmsford (2011)

11. Hilmola, O.-P. 'Environmental and infrastructure payments and the future of road transports: case Tallinn-Warsaw', World Review of Intermodal Transportation Research, Vol. 4 No. 1, pp. 55 (2013)

12. Hämäläinen, E., Twrdy, E. and Inkinen, T. 'Cost aggregation in logistic chain', Journal of Open Innovation: Techhnology, Market, and Complexity, Vol. 3 No. 26, pp. 1-14 (2017) 
13. Wiesmann, A. 'Slow steaming - a viable long-term option?', Wärtsilä Technical Journal, February (2010) 